\title{
The survival rate of extremely low birth weight infants improved in Guangdong Province, China
}

\section{Fan Wu ( gdwufan@126.com )}

Guangzhou Medical University https://orcid.org/0000-0002-8564-4619

\section{Chun-Hong Jia}

The Third Affiliated Hospital of Guangzhou Medical University

\section{Zhou-Shan Feng}

The Third Affiliated Hospital of Guangzhou Medical University

Xiao-Jun Lin

The Third Affiliated Hospital of Guangzhou Medical University

\section{Qi-Liang Cui}

The Third Affiliated Hospital of Guangzhou Medical University

\section{Sha-Sha Han}

Jinan University First Affiliated Hospital

Ya Jin

Jinan University First Affiliated Hospital

Guo-Sheng Liu

Jinan University First Affiliated Hospital

Chuan-Zhong Yang

Shenzhen Women's and Children's Hospital

Xiao-Tong Ye

Shenzhen Woman's and Children's Hospital

Yi-Heng Dai

Foshan Women's and Children's Hospital

Wei-Yi Liang

Foshan Women's and Children's Hospital

Xiu-Zhen Ye

Guangdong Women's and Children's Hospital

Jing Mo

Guangdong Women's and Children's Hospital

Lu Ding

Shenzhen People's Hospital

\section{Ben-Qing Wu}

Shenzhen People's Hospital

Hong-Xiang Chen

Meizhou People's Hospital

\section{Chi-Wang Li}

Meizhou People's Hospital

\section{Zhe Zhang}

Guangzhou Women and Children's Medical Center

\section{Xiao Rong}

Guangzhou Women and Children's Medical Center

Wei-Min Huang

Southern Medical University Nanfang Hospital 


\section{Wei Shen}

Southern Medical University Nanfang Hospital

\section{Bing-Yan Yang}

Zhongshan Boai Hospital

Jun-Feng Lv

Zhongshan Boai Hospital

\section{Le-Ying Huo}

Zhuhai Women's and Children's Hospital

\section{Hui-Wen Huang}

Zhuhai Women's and Children's Hospital

\section{Hong-Ping Rao}

Huizhou Central People's Hospital

\section{Wen-Kang Yan}

Huizhou Central People's Hospital

\section{Yong Yang}

Dongguan Women's and Children's Hospital

\section{Xue-Jun Ren}

Dongguan Women's and Children's Hospital

\section{Dong Liu}

Jiangmen Central Hospital

\section{Fang-Fang Wang}

Jiangmen Central Hospital

\section{Shi-Guang Diao}

Yuebei People's Hospital

Xiao-Yan Liu

Yuebei People's Hospital

\section{Chu-Ming You}

Guangdong Second Provincial General Hospital

\section{Qiong Meng}

Guangdong Second Provincial General Hospital

\section{Bin Wang}

Zhujiang Hospital of Southern Medical University

\section{Li-Juan Zhang}

Zhujiang Hospital of Southern Medical University

\section{Yu-Ge Huang}

Guangdong Medical University affiliated Children's Medical Center

\section{Dang Ao}

Guangdong Medical University affiliated Children's Medical Center

\section{Wei-Zhong Li}

The second affiliated Hospital of Shantou University

\section{Jie-Ling Chen}

The Second Affiliated Hospital of Shantou University

\section{Yan-Ling Chen}

Jinan University Affiliated Dongguan Hospital: Binhaiwan Central Hospital of Dongguan

\section{Wei Li}

Jinan University Affiliated Dongguan Hospital: Binhaiwan Central Hospital of Dongguan

\section{Zhi-Feng Chen}

Dongguan People's Hospital

\section{Yue-Qin Ding}


Dongguan People's Hospital

\section{Xiao-Yu Li}

Sun Yat-sen University First Affiliated Hospital

\section{Yue-Fang Huang}

Sun Yat-sen University First Affiliated Hospital

\section{Ni-Yang Lin}

The First affiliated Hospital of Shantou University

\section{Yang-Fan Cai}

The First Affiliated Hospital of Shantou University

\section{Zhong-He Wan}

Foshan Nanhai District People's Hospital

\section{Yi Ban}

Foshan Nanhai District People's Hospital

\section{Bo Bai}

Guangzhou Huadu District People's Hospital

\section{Guang-Hong Li}

Guangzhou Huadu District People's Hospital

\section{Yue-Xiu Yan}

Zhaoqing First People's Hospital

\section{Research}

Keywords: Extremely low birth weight, Preterm infant, Outcome, Mortality, Complication, China

Posted Date: November 8th, 2021

DOI: https://doi.org/10.21203/rs.3.rs-1019118/v1

License: () (i) This work is licensed under a Creative Commons Attribution 4.0 International License. Read Full License 


\section{Abstract \\ Background}

With the increase in extremely low birth weight (ELBW) infants, their outcomes received special attention. However, in China, studies of the outcomes of ELBW infants are rare.

\section{Methods}

The hospitalized records of ELBW infants discharged from twenty-six neonatal intensive care units were reviewed and analyzed.

\section{Results}

A total of 2575 ELBW infants were enrolled and the overall survival rate was $55.11 \%$. From 2008 to 2017 , the number of ELBW infants increased rapidly from 91 to 466, and the survival rate improved steadily from 41.76-62.02\%. The survival rate rose with increasing BW, the ascending level of regional economic development and specialist hospitals. The incidence of complications was neonatal respiratory distress syndrome (85.2\%), bronchopulmonary dysplasia (63.7\%), retinopathy of prematurity (39.3\%), intraventricular hemorrhage (29.4\%), necrotizing enterocolitis (12.0\%), and periventricular leukomalacia (8.0\%). Among the 1156 nonsurvivors, $90.0 \%$ of infants died during the neonatal period ( $\leq 28$ days), and the other died after the neonatal period. A total of 768 ELBW infants died after medical care withdrawal, with economic factors and expected outcome being important causes.

\section{Conclusion}

The number of ELBW infants is increasing in China, and the overall survival rate is still low but is improving steadily.

\section{Introduction}

Low birth weight premature infants have a particularly high risk for morbidity and mortality[1, 2]. In recent decades, the outcomes of preterm infants, especially extremely preterm (gestational age $[\mathrm{GA}]<28$ weeks) and extremely low birth weight (ELBW, birth weight [BW] $<1000$ grams) infants, have improved worldwide due to the use of antenatal steroids, pulmonary surfactant treatment and advances in perinatal health care, such as neonatal resuscitation, mechanical ventilation and nutritional management[3-6]. However, mortality and morbidity vary widely across countries or regions. Generally, more improvements have been gained in developed countries or regions, such as the United States[2, 7], the United Kingdom[8], Japan[9, 10] and Singapore[11].

\section{Methods}

\section{Participating centers}

The membership of the collaborative study group was the same as previously described ${ }^{17}$. In brief, twenty-six NICUs were united as a collaborative study group before clinical data collection. These NICUs were located in three regions with different economic development levels in Guangdong Province and were representative of medical units offering neonatal intensive care in their respective areas as we described before[17]. The Third Affiliated Hospital of Guangzhou Medical University was responsible for coordinating this study. This survey was approved by the Ethics Committees of the Third Affiliated Hospital of Guangzhou Medical University. The same diagnostic criteria were applied to all enrolled NICUs.

\section{Subjects and data collection}

All ELBW infants discharged from the collaborative NICUs were studied. The study protocol was fully discussed by all members, and a standardized questionnaire for data collection, including maternal and neonatal demographics, treatments, major complications and outcomes, was designed. The study was initiated at the end of 2012 and is still ongoing. Therefore, the data from January 1 , 2008, to December 31, 2012, were collected retrospectively, and data from January 1, 2013, to December 31, 2017, were collected 
prospectively. The relevant records of all enrolled infants and their mothers were reviewed, and a questionnaire was completed. All sheets were sent to the Third Affiliated Hospital of Guangzhou Medical University, and the data from each questionnaire were input into the database. To minimize bias among centers and investigators, comprehensive and systematic training was provided to the staff involved in the survey. The data collected by the researchers at each collaborative NICU were supervised and checked by the director of the NICU, who was responsible for quality assurance. The records were also checked for accuracy and completeness by collaborative centers.

\section{Definitions and classifications}

In this survey, surviving infants were defined as neonates who survived to the time of discharge. GA was calculated from the date of the last menstrual period or was determined by fetal ultrasound assessment. Neonatal respiratory distress syndrome (NRDS) was diagnosed in preterm infants with the onset of respiratory distress shortly after birth and a compatible chest radiograph appearance[18]. Bronchopulmonary dysplasia (BPD) was defined as continuous oxygen dependency at 28 days of age[19]. The criteria utilized in our survey for the diagnosis of necrotizing enterocolitis (NEC) and for grading the severity of disease were based on Bell's stage[20]. Retinopathy of prematurity (ROP) and the graded standard were defined by the international classification of ROP[21]. Intraventricular hemorrhage (IVH) and periventricular leukomalacia (PVL) were diagnosed by cranial ultrasonography or magnetic resonance imaging (MRI). The Papile grading system was used to grade IVH[22], and PVL was defined as degeneration of white matter adjacent to the cerebral ventricles following cerebral hypoxia or brain ischemia[23].

\section{Statistical analysis}

All statistical analyses were performed using SPSS 18.0 for Windows (IBM, Armonk, NY, USA). Continuous variables were presented as the means \pm standard deviation $(S D)$ when their distributions were highly skewed or as medians $(P 25, P 75)$ when their distributions were not skewed and were analyzed using $t$-tests or Mann-Whitney tests. Categorical variables were presented as rates and odds ratios with $95 \%$ confidence intervals $(\mathrm{Cls})$, which were analyzed using chi-square tests. $\mathrm{P}<0.05$ was considered statistically significant.

\section{Results}

\section{Demographics of ELBW infants and mothers}

From 2008 to 2017, 2575 ELBW infants were enrolled in this survey. The overall survival rate at discharge was $55.11 \%$ (1419 of 2575). The lowest BW in the survivors was 480 grams. In total, the median BW was $900(800,950)$ grams, and the distribution ranged from $22(0.85 \%)$ for less than 500 grams, $52(2.02 \%)$ for $500-599$ grams, 150 (5.83\%) for $600-699$ grams, 372 (14.45\%) for 700 - 799 grams, $685(26.60 \%)$ for $800-899$ grams to $1294(50.25 \%)$ for $900-999$ grams. The mean GA was $27.96 \pm 2.06$ weeks, and the distribution ranged from $26(1.01 \%)$ for less than 24 weeks, 102 (3.96\%) for 24 weeks, $246(9.55 \%)$ for 25 weeks, 420 (16.31\%) for 26 weeks, 515 (20.00\%) for 27 weeks, 521 (20.23\%) for 28 weeks, 315 (12.23\%) for 29 weeks to 430 (16.70\%) for equal to or above 30 weeks.

To clarify the current treatment and outcome of ELBW infants, we specifically grouped the ELBW infants based on whether they survived, as presented in Table 1. Both the BW and GA in the survivor group were greater than those in the nonsurvivor group ( $p<$ 0.001). In the survivor group, there were fewer infants with Apgar scores $\leq 3$ at $1 \mathrm{~min}$ and $\leq 3$ or $4 \llbracket 7$ at $5 \mathrm{~min}$ (all $p<0.001$ ). The survivor group had a longer hospital stay and a higher rate of receiving surfactant therapy $(p<0.001)$, but there was no significant difference between those who required two or more doses of surfactant therapy. No significant difference in sex was found between the survivor and nonsurvivor groups. 
Table 1

Demographics of extremely low birth weight (ELBW) infants and the mothers in outcome categories

\begin{tabular}{|c|c|c|c|c|}
\hline Characteristics & $\begin{array}{l}\text { Survivors } \\
(\mathrm{N}=1419)\end{array}$ & $\begin{array}{l}\text { Non-survivors } \\
(\mathrm{N}=1156)\end{array}$ & OR $(95 \% C l)$ & $p$-value \\
\hline \multicolumn{5}{|l|}{ Characteristics of infants } \\
\hline Gender (male), n (\%) & $745(52.50)$ & $623(53.89)$ & $\begin{array}{l}0.946(0.809- \\
1.105)\end{array}$ & NS \\
\hline GA (weeks), mean \pm SD & $28.37 \pm 1.95$ & $27.45 \pm 2.08$ & / & $\varangle 0.001$ \\
\hline BW (grams), median (P25, P75) & $\begin{array}{l}910(840, \\
960)\end{array}$ & $850(750,930)$ & / & $\varangle 0.001$ \\
\hline \multicolumn{5}{|l|}{ Apgar score, n (\%) } \\
\hline$\leq 3$ at $1 \mathrm{~min}$ & $125(8.81)$ & $209(18.08)$ & $\begin{array}{l}0.438(0.345- \\
0.555)\end{array}$ & $₫ 0.001$ \\
\hline $4 \sim 7$ at $1 \mathrm{~min}$ & $479(33.76)$ & $431(37.28)$ & $\begin{array}{l}0.857(0.729- \\
1.008)\end{array}$ & NS \\
\hline$\leq 3$ at $5 \mathrm{~min}$ & $14(0.99)$ & $48(4.15)$ & $\begin{array}{l}0.230(0.126- \\
0.498)\end{array}$ & $\varangle 0.001$ \\
\hline $4 \sim 7$ at $5 \mathrm{~min}$ & $148(10.23)$ & $251(21.71)$ & $\begin{array}{l}0.420(0.337- \\
0.523)\end{array}$ & $\varangle 0.001$ \\
\hline Surfactant therapy (any dose), n (\%) & $1150(81.04)$ & $801(69.29)$ & $\begin{array}{l}1.895(1.579- \\
2.274)\end{array}$ & $\varangle 0.001$ \\
\hline Surfactant therapy (two doses or more), $\mathrm{n}(\%)$ & $166(11.70)$ & $164(14.19)$ & $\begin{array}{l}0.801(0.636- \\
1.010)\end{array}$ & NS \\
\hline $\begin{array}{l}\text { Length of hospital stay (days), median (P25, } \\
\text { P75) }\end{array}$ & $69(53,85)$ & $3(1,11)$ & / & $\varangle 0.001$ \\
\hline \multicolumn{5}{|l|}{ Characteristics of mothers } \\
\hline History of bad motherhood ${ }^{a}, \mathrm{n}(\%)$ & $589(41.51)$ & $452(39.10)$ & $\begin{array}{l}1.105(0.943- \\
1.295)\end{array}$ & NS \\
\hline Age $\geq 35$ years, $n(\%)$ & $310(21.85)$ & $221(19.12)$ & $\begin{array}{l}1.183(0.975- \\
1.435)\end{array}$ & NS \\
\hline Cesarean section, n (\%) & $691(48.70)$ & 399 (34.52) & $\begin{array}{l}1.801(1.535- \\
2.113)\end{array}$ & $\varangle 0.001$ \\
\hline Twin/multiple pregnancy, n (\%) & $530(37.35)$ & $466(40.31)$ & $\begin{array}{l}0.883(0.753- \\
1.035)\end{array}$ & NS \\
\hline Antenatal corticosteroid, $\mathrm{n}(\%)$ & $800(56.38)$ & $467(40.40)$ & $\begin{array}{l}1.907(1.629- \\
2.232)\end{array}$ & $\varangle 0.001$ \\
\hline Premature rupture of membranes, $\mathrm{n}(\%)$ & $342(24.10)$ & $203(17.56)$ & $\begin{array}{l}1.491(1.228- \\
1.810)\end{array}$ & $\varangle 0.001$ \\
\hline Infection in perinatal period, $\mathrm{n}(\%)$ & $78(5.50)$ & $62(5.36)$ & $\begin{array}{l}1.026(0.728- \\
1.446)\end{array}$ & NS \\
\hline Gestational diabetes mellitus, n (\%) & $123(8.67)$ & $84(7.27)$ & $\begin{array}{l}1.211(0.907- \\
1.617)\end{array}$ & NS \\
\hline Pregnancy induced hypertension syndrome, $\mathrm{n}(\%)$ & $398(28.05)$ & $240(20.76)$ & $\begin{array}{l}1.488(1.239- \\
1.787)\end{array}$ & $\varangle 0.001$ \\
\hline \multicolumn{5}{|c|}{$\begin{array}{l}\text { aHistory of bad motherhood refers to that the mother had at least one of the histories as follow: spontaneous abortion, induced } \\
\text { abortion, stillbirth, preterm birth, ectopic pregnancy, or baby died during neonatal period. GA: Gestational age; BW: Birth weight; } \\
\text { SD: Standard deviation; P25: The 25th percentile; P75: The 75th percentile; OR: Odds ratio; Cl: Confidence intervals; NS: No } \\
\text { significant difference. }\end{array}$} \\
\hline
\end{tabular}




\begin{tabular}{|c|c|c|c|c|}
\hline Characteristics & $\begin{array}{l}\text { Survivors } \\
(\mathrm{N}=1419)\end{array}$ & $\begin{array}{l}\text { Non-survivors } \\
(\mathrm{N}=1156)\end{array}$ & OR $(95 \% C l)$ & $p$-value \\
\hline Placental abruption/Placenta previa, n (\%) & $115(8.10)$ & $101(8.74)$ & $\begin{array}{l}0.921(0.697- \\
1.218)\end{array}$ & NS \\
\hline Cervical incompetence, $\mathrm{n}(\%)$ & $20(1.41)$ & $35(3.03)$ & $\begin{array}{l}0.458(0.263- \\
0.798)\end{array}$ & $\varangle 0.01$ \\
\hline Fetal distress, n (\%) & $108(7.61)$ & $64(5.54)$ & $\begin{array}{l}1.406(1.021- \\
1.935)\end{array}$ & $\otimes 0.05$ \\
\hline \multicolumn{5}{|c|}{$\begin{array}{l}\text { aHistory of bad motherhood refers to that the mother had at least one of the histories as follow: spontaneous abortion, induced } \\
\text { abortion, stillbirth, preterm birth, ectopic pregnancy, or baby died during neonatal period. GA: Gestational age; BW: Birth weight; } \\
\text { SD: Standard deviation; P25: The 25th percentile; P75: The 75th percentile; OR: Odds ratio; Cl: Confidence intervals; NS: No } \\
\text { significant difference. }\end{array}$} \\
\hline
\end{tabular}

The mothers in the survivor group had a higher proportion of antenatal steroid therapy and cesarean section (both $p<0.001)$ but a lower incidence of cervical incompetence $(p<0.01)$. Interestingly, the mothers in the survivor group even had higher incidences of premature rupture of membranes $(p<0.001)$, fetal distress $(p<0.05)$ and pregnancy-induced hypertension syndrome $(p<0.001)$. Between the survivor and nonsurvivor groups, there was a similar incidence in the history of pregnancy problems, as in mother's age ( $\geq 35$ years), multiple pregnancy (twins/triplets), infection in the perinatal period, gestational diabetes mellitus, or placental disease (placental abruption/placenta previa).

Both the number and survival rates of ELBW infants increased from 2008 to 2017. The number of ELBW infants discharged from the involved NICUs increased rapidly from 91 cases in 2008 to 466 cases in 2017, as shown in Table 2. Moreover, the proportion of ELBW infants among all discharged preterm infants rose annually from $1.09 \%$ in 2008 to $2.62 \%$ in 2017 ( $p<0.001$ ), and the proportion of ELBW infants among all discharged infants increased annually from $0.27 \%$ in 2008 to $0.77 \%$ in 2017 ( $p<0.001$, Fig. 1). It was encouraging that the survival rate of ELBW infants improved steadily from $41.76 \%$ in 2008 to $62.02 \%$ in 2017 ( $p<$ 0.001 , Table 2).

Table 2

The survival rate of extremely low birth weight (ELBW) infants at discharge from 2008 to 2017

\begin{tabular}{|c|c|c|c|c|c|c|c|c|c|c|c|}
\hline $\begin{array}{l}\text { Discharged } \\
\text { year }\end{array}$ & 2008 & 2009 & 2010 & 2011 & 2012 & 2013 & 2014 & 2015 & 2016 & 2017 & $\begin{array}{l}p- \\
\text { value }\end{array}$ \\
\hline $\begin{array}{l}\text { ELBW } \\
\text { infants, } n\end{array}$ & 91 & 102 & 114 & 237 & 210 & 244 & 308 & 340 & 463 & 466 & / \\
\hline $\begin{array}{l}\text { Survived, n } \\
\text { (\%) }\end{array}$ & $\begin{array}{l}38 \\
(41.76)\end{array}$ & $\begin{array}{l}48 \\
(47.06)\end{array}$ & $\begin{array}{l}56 \\
(49.12)\end{array}$ & $\begin{array}{l}110 \\
(46.41)\end{array}$ & $\begin{array}{l}110 \\
(52.38)\end{array}$ & $\begin{array}{l}136 \\
(55.74)\end{array}$ & $\begin{array}{l}164 \\
(53.25)\end{array}$ & $\begin{array}{l}195 \\
(57.35)\end{array}$ & $\begin{array}{l}273 \\
(58.96)\end{array}$ & $\begin{array}{l}289 \\
(62.02)\end{array}$ & $\nabla 0.001$ \\
\hline $\begin{array}{l}\text { Died } \\
\text { despite } \\
\text { active } \\
\text { treatment, } \\
\mathrm{n}(\%)\end{array}$ & $\begin{array}{l}13 \\
(14.29)\end{array}$ & $\begin{array}{l}14 \\
(13.73)\end{array}$ & $\begin{array}{l}17 \\
(14.91)\end{array}$ & $\begin{array}{l}39 \\
(16.45)\end{array}$ & $\begin{array}{l}23 \\
(10.95)\end{array}$ & $\begin{array}{l}27 \\
(11.07)\end{array}$ & $\begin{array}{l}57 \\
(18.51)\end{array}$ & $\begin{array}{l}61 \\
(17.94)\end{array}$ & $\begin{array}{l}77 \\
(16.63)\end{array}$ & $\begin{array}{l}60 \\
(12.88)\end{array}$ & I \\
\hline $\begin{array}{l}\text { Died after } \\
\text { medical } \\
\text { care } \\
\text { withdrawal, } \\
\mathrm{n}(\%)\end{array}$ & $\begin{array}{l}40 \\
(43.96)\end{array}$ & $\begin{array}{l}40 \\
(39.22)\end{array}$ & $\begin{array}{l}41 \\
(35.96)\end{array}$ & $\begin{array}{l}88 \\
(37.13)\end{array}$ & $\begin{array}{l}77 \\
(36.67)\end{array}$ & $\begin{array}{l}81 \\
(33.20)\end{array}$ & $\begin{array}{l}87 \\
(28.25)\end{array}$ & $\begin{array}{l}84 \\
(24.71)\end{array}$ & $\begin{array}{l}113 \\
(24.41)\end{array}$ & $\begin{array}{l}117 \\
(25.11)\end{array}$ & I \\
\hline
\end{tabular}

\section{Survival rates of ELBW infants improved with increasing BW}

With the increase in BW, the number of ELBW infants increased sharply from 22 in the group with BW < 500 grams to 1294 in the group with BW 900 - 999 grams, as demonstrated in Table 3. Only one infant survived with BW < 500 grams. However, the survival 
rate rose dramatically from $30.77 \%$ in the group with BW $500-599$ grams to $65.53 \%$ in the group with BW $900-999$ grams (p< 0.001). Of course, the survival rate of infants weighing $500-749$ grams was lower than that of infants weighing $750-999$ grams (35.15\% (129 of 367$)$ vs. $58.97 \%$ (1289 of 2186$), \mathrm{OR}=0.377,95 \% \mathrm{Cl}: 0.300-0.475, \mathrm{p}<0.001)$.

Table 3

The survival rate of extremely low birth weight (ELBW) infants in relation to birth weight

\begin{tabular}{|c|c|c|c|c|c|c|c|}
\hline Birth weight (grams) & $\mathbf{8 5 0 0}$ & $500 \sim 599$ & $600 \sim 699$ & $700 \sim 799$ & $800 \sim 899$ & $900 \sim 999$ & $p$-value \\
\hline ELBW infants, $n$ & 22 & 52 & 150 & 372 & 685 & 1294 & / \\
\hline \multirow[t]{2}{*}{ Survived, n (\%) } & 1 & 16 & 46 & 145 & 363 & 848 & $\varangle 0.001$ \\
\hline & $(4.55)$ & $(30.77)$ & $(30.67)$ & $(38.98)$ & $(52.99)$ & $(65.53)$ & \\
\hline \multirow[t]{2}{*}{ Died despite active treatment, $\mathrm{n}(\%)$} & 2 & 15 & 43 & 63 & 110 & 155 & / \\
\hline & $(9.09)$ & $(28.85)$ & $(28.67)$ & $(16.94)$ & $(16.06)$ & $(11.98)$ & \\
\hline \multirow[t]{2}{*}{ Died after medical care withdrawal, n (\%) } & 19 & 21 & 61 & 164 & 212 & 291 & / \\
\hline & $(86.36)$ & $(40.38)$ & $(40.67)$ & (44.09) & $(30.95)$ & (22.49) & \\
\hline
\end{tabular}

\section{Variations in survival rates among different regions}

According to the level of economic development where the NICUs were located, the collaborative NICUs could be divided into three categories. Specifically, Guangzhou and Shenzhen (including eleven NICUs) had a high level, the other cities in the Pearl Delta (including ten NICUs) had a medium level, and the cities outside the Pearl Delta (including five NICUs) had a low level of development. From the low to the high level, the mean GA of ELBW infants was $28.26 \pm 2.04$ weeks, $28.13 \pm 2.01$ weeks and $27.80 \pm$ 2.08 weeks, which showed a mild deceasing tendency $(r=0.090, p<0.001)$, while no significant difference was found in BW (the median BW was $885(800,950)$ grams, $900(813,960)$ grams and $890(790,950)$ grams, respectively). However, the overall survival rates increased with the ascending level of regional economic development $(p<0.05)$. This is shown in Table 4.

Table 4

Differences of survival rate among regions or between hospitals

\begin{tabular}{|c|c|c|c|c|c|c|c|}
\hline & \multicolumn{4}{|c|}{ Economic development levels of region } & \multicolumn{3}{|c|}{ Types of hospital } \\
\hline & $\begin{array}{l}\text { Low- } \\
\text { level }\end{array}$ & $\begin{array}{l}\text { Middle- } \\
\text { level }\end{array}$ & $\begin{array}{l}\text { High- } \\
\text { level }\end{array}$ & $\begin{array}{l}\mathrm{p}- \\
\text { value }\end{array}$ & $\begin{array}{l}\text { Specialist } \\
\text { hospitals }\end{array}$ & $\begin{array}{l}\text { General } \\
\text { hospitals }\end{array}$ & $\begin{array}{l}\mathrm{p}- \\
\text { value }\end{array}$ \\
\hline NICUs, $\mathrm{n}$ & 5 & 10 & 11 & / & 7 & 19 & / \\
\hline ELBW infants, $n$ & 352 & 728 & 1495 & / & 1068 & 1507 & / \\
\hline Survived, n (\%) & $\begin{array}{l}175 \\
(49.72)\end{array}$ & $\begin{array}{l}400 \\
(54.95)\end{array}$ & $\begin{array}{l}844 \\
(56.45)\end{array}$ & $\varangle 0.05$ & $642(60.11)$ & $777(51.56)$ & $\varangle 0.001$ \\
\hline $\begin{array}{l}\text { Died despite active treatment, } \mathrm{n} \\
(\%)\end{array}$ & $\begin{array}{l}69 \\
(19.60)\end{array}$ & $\begin{array}{l}93 \\
(12.77)\end{array}$ & $\begin{array}{l}226 \\
(15.12)\end{array}$ & / & $133(12.45)$ & $255(16.92)$ & / \\
\hline $\begin{array}{l}\text { Died after medical care } \\
\text { withdrawal, } \mathrm{n}(\%)\end{array}$ & $\begin{array}{l}108 \\
(30.68)\end{array}$ & $\begin{array}{l}235 \\
(32.28)\end{array}$ & $\begin{array}{l}425 \\
(28.43)\end{array}$ & / & $293(27.43)$ & $475(31.52)$ & / \\
\hline \multicolumn{8}{|c|}{$\begin{array}{l}\text { R } \times 2 \text { Chi-square test (linear-by-linear association) showed that the overall survival rate of ELBW infants discharged from different } \\
\text { regions improved with the ascending level of economic development }(P \otimes 0.05) \text {. And } 2 \times 2 \text { Chi-square test showed that the survival } \\
\text { rate of ELBW infants discharged from specialist hospitals was higher than those from general hospitals }(P \otimes 0.001) \text {. NICUs: } \\
\text { Neonatal intensive care units; ELBW: Extremely low birth weight. }\end{array}$} \\
\hline
\end{tabular}

\section{Variations in survival rates between general hospitals and specialist hospitals}


Among the twenty-six NICUs involved, seven were in specialist hospitals (maternal and children's hospitals), and the others were in general hospitals. The median BW and mean GA of ELBW infants discharged from specialist hospitals $(880(790,950)$ grams and $27.59 \pm 2.03$ weeks, respectively) were both smaller than those of infants discharged from general hospitals $(900(800,950)$ grams and $28.22 \pm 2.05$ weeks, respectively, both $p<0.001)$. However, the overall survival rate of ELBW infants discharged from specialist hospitals was higher than that of infants discharged from general hospitals $(\mathrm{OR}=1.416,95 \% \mathrm{Cl}: 1.208-1.660, \mathrm{p}<0.001)(\mathrm{Table}$ 4).

\section{Complications of ELBW infants during hospitalization}

The incidence of complications was high in ELBW infants: $85.2 \%$ for NRDS, $63.7 \%$ for BPD at 28 days of age, $39.3 \%$ for ROP, $29.4 \%$ for IVH, $12.0 \%$ for NEC and $8.0 \%$ for PVL in total. The calculated incidence of complications in each BW group is listed in Table 5 . To identify the difference relative to BW, comparisons were made between groups with BW 500-749 grams and 750-999 grams. The group with BW 500-749 grams had higher incidence than the group with BW 750-999 grams in NRDS (91.3\% vs. 84.0\%, OR=1.989, 95\% Cl:1.360-2.909, p < 0.001), BPD (83.3\% vs. 61.4\%, OR=3.144, 95\% Cl: 1.981-4.989, p < 0.001), ROP (49.4\% vs. 38.2\%, OR=1.580, $95 \%$ Cl: $1.139-2.191, \mathrm{p}<0.01)$ or ROP above stage III (19.8\% vs. 9.0\%, OR=2.498, 95\% Cl: 1.626-3.838, p < 0.001), IVH (37.7\% vs. $27.9 \%, \mathrm{OR}=1.564,95 \% \mathrm{Cl}: 1.178-2.078, \mathrm{p}<0.01)$ or severe IVH (15.5\% vs. $6.3 \%, \mathrm{OR}=2.708,95 \% \mathrm{Cl}: 1.807-4.057, \mathrm{p}<0.001)$, and NEC (17.2\% vs. $11.4 \%, \mathrm{OR}=1.615,95 \% \mathrm{Cl}: 1.118-2.333, \mathrm{p}<0.05)$. There was no significant difference in the incidence of NEC above stage Ilb (2.9\% vs. $1.7 \%$, OR=1.705, 95\% Cl: $0.740-3.925)$ or PVL (5.4\% vs. 8.5\%, OR=0.622, 95\% Cl: 0.346-1.117) between the two groups (Fig. 2). 
Table 5

The incidence of complications during hospitalization in ELBW infants

\begin{tabular}{|c|c|c|c|c|c|c|c|}
\hline & $\begin{array}{l}\otimes 500 g \\
(n=22)\end{array}$ & $\begin{array}{l}500-599 g \\
(n=52)\end{array}$ & $\begin{array}{l}600-699 g \\
(n=150)\end{array}$ & $\begin{array}{l}700-799 g \\
(n=372)\end{array}$ & $\begin{array}{l}800-899 g \\
(n=685)\end{array}$ & $\begin{array}{l}900-999 g \\
(n=1294)\end{array}$ & $\begin{array}{l}\text { Total } \\
(n=2575)\end{array}$ \\
\hline \multicolumn{8}{|l|}{ NRDS } \\
\hline Assessed, n & 22 & 52 & 150 & 372 & 685 & 1294 & 2575 \\
\hline Diagnosed, n (\%) & $21(95.5)$ & $46(88.5)$ & $141(94.0)$ & 331(89.0) & $579(84.5)$ & 1075(83.1) & 2193(85.2) \\
\hline \multicolumn{8}{|l|}{$\begin{array}{l}\text { BPD at } 28 \text { days of } \\
\text { age }\end{array}$} \\
\hline Assessed, $\mathrm{n}$ & 5 & 18 & 58 & 140 & 360 & 821 & 1402 \\
\hline Diagnosed, n (\%) & $5(100.0)$ & 16(88.9) & $46(79.3)$ & 111(79.3) & 249(69.2) & $466(56.8)$ & 893(63.7) \\
\hline \multicolumn{8}{|l|}{ ROP } \\
\hline Assessed, $\mathrm{n}$ & 5 & 22 & 71 & 187 & 412 & 819 & 1516 \\
\hline $\begin{array}{l}\text { Diagnosed (any } \\
\text { grade), n (\%) }\end{array}$ & $1(20.0)$ & $10(45.5)$ & $32(45.1)$ & $77(41.2)$ & 155(37.6) & $321(39.2)$ & 596(39.3) \\
\hline $\begin{array}{l}\text { Diagnosed ( } \geq \text { grade } \\
\text { 3), n (\%) }\end{array}$ & 0 & $8(36.4)$ & $10(14.1)$ & $29(15.5)$ & $44(10.7)$ & $62(7.6)$ & 153(10.1) \\
\hline \multicolumn{8}{|l|}{ NEC } \\
\hline Assessed, $\mathrm{n}$ & 12 & 38 & 102 & 242 & 508 & 1074 & 1976 \\
\hline $\begin{array}{l}\text { Diagnosed (any } \\
\text { stage), n (\%) }\end{array}$ & 0 & $6(15.8)$ & 19(18.6) & $32(13.2)$ & $52(10.2)$ & 128(11.9) & $237(12.0)$ \\
\hline $\begin{array}{l}\text { Diagnosed ( } \geq \text { stage } \\
\text { 冈b), n (\%) }\end{array}$ & 0 & $1(2.6)$ & $5(4.9)$ & $5(2.1)$ & $15(3.0)$ & $21(2.0)$ & $37(1.9)$ \\
\hline \multicolumn{8}{|l|}{ IVH } \\
\hline Assessed, $\mathrm{n}$ & 12 & 38 & 92 & 252 & 493 & 958 & 1845 \\
\hline $\begin{array}{l}\text { Diagnosed (any } \\
\text { grade), n (\%) }\end{array}$ & $8(66.7)$ & 15(39.5) & $38(41.3)$ & $95(37.7)$ & $140(28.4)$ & $246(25.7)$ & $542(29.4)$ \\
\hline $\begin{array}{l}\text { Diagnosed ( } \geq \text { grade } \\
\text { ఐ), } n(\%)\end{array}$ & $6(50.0)$ & $6(15.8)$ & $16(17.4)$ & $32(12.7)$ & $33(6.7)$ & $51(5.3)$ & $144(7.8)$ \\
\hline \multicolumn{8}{|l|}{ PVL } \\
\hline Assessed, n & 12 & 38 & 92 & 252 & 493 & 958 & 1845 \\
\hline Diagnosed, n (\%) & $0(0)$ & $1(2.6)$ & $5(5.4)$ & $20(7.9)$ & $45(9.1)$ & $77(8.0)$ & $148(8.0)$ \\
\hline \multicolumn{8}{|c|}{$\begin{array}{l}\text { BPD was assessed in infants who survived more than } 28 \text { days. ROP was assessed in infants who had undergone fundus } \\
\text { examination. NEC was assessed in infants who survived more than } 48 \text { hours. IVH and PVL were assessed in infants who had } \\
\text { undergone transcranial ultrasound or MRI examination. NRDS: Neonatal respiratory distress syndrome; BPD: Bronchopulmonary } \\
\text { dysplasia; ROP: Retinopathy of prematurity; NEC: Necrotizing enterocolitis; IVH: Intraventricular hemorrhage; PVL: Periventricular } \\
\text { leukomalacia. }\end{array}$} \\
\hline
\end{tabular}

\section{Survival days of the nonsurvivors and the causes for care withdrawal}

Among the 1156 nonsurvivors, $90.0 \%$ (1040 of 1156) of infants died during the neonatal period ( $\leq 28$ days), and the other $10.0 \%$ (116 of 1156) died after the neonatal period (> 28 days). Specifically, $27.2 \%$ (314 of 1156) of infants died during the first 24 hours, $16.4 \%$ (190 of 1156) on the second day, $9.4 \%$ (109 of 1156) on the third day, $15.2 \%$ (176 of 1156) during the fourth to seven days, $9.7 \%$ (112 of 1156 ) in the second week, $7.4 \%$ (85 of 1156) in the third week and $4.7 \%$ (54 of 1156 ) in the fourth week. The survival 
days (or hours) of nonsurvivors under active treatment or after medical care withdrawal are shown in Table 6. The chi-square test showed that there was a significant difference in the distribution of survival days between the two groups $(p<0.001)$.

Table 6

Survival days (or hours) of the non-survivors

\begin{tabular}{|c|c|c|c|c|c|c|c|c|}
\hline \multirow[t]{2}{*}{ Age of death } & \multicolumn{4}{|l|}{ ENP } & \multicolumn{3}{|l|}{ LNP } & \multirow{2}{*}{ 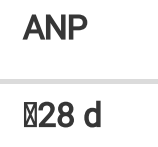 } \\
\hline & $\leq 24 \mathrm{~h}$ & $凶 2 \mathrm{~d}$ & घ3 d & Q7 d & Q14 d & 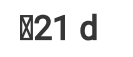 & $\llbracket 28 \mathrm{~d}$ & \\
\hline $\begin{array}{l}\text { Died despite active } \\
\text { treatment, } \mathrm{n}(\%)\end{array}$ & $80(20.6)$ & $58(14.9)$ & $33(8.5)$ & $57(14.7)$ & $43(11.1)$ & $26(6.7)$ & $25(6.4)$ & $66(17.0)$ \\
\hline $\begin{array}{l}\text { Died after medical } \\
\text { care withdrawal, n (\%) }\end{array}$ & $234(30.5)$ & 132(17.2) & $76(9.9)$ & $119(15.5)$ & $69(9.0)$ & $59(7.7)$ & $29(3.8)$ & $50(6.5)$ \\
\hline Total, n (\%) & $314(27.2)$ & 190(16.4) & $109(9.4)$ & $176(15.2)$ & $112(9.7)$ & $85(7.4)$ & $54(4.7)$ & $116(10.0$ \\
\hline
\end{tabular}

In this study, 768 ELBW infants died after medical care withdrawal. The causes were summarized and analyzed. Economic and outcome factors were both important. More specifically, for $35.9 \%$ (276 of 768) of infants, there were concerns about the economic burden together with the fear of poor or uncertain outcomes; for $29.6 \%$ (227 of 768) of infants, there were only fears of poor or uncertain outcomes; and for $14.7 \%$ (113 of 768 ) of infants, there were concerns only about the economic burden. For $1.6 \%$ (12 of 768) of infants, medical care was withdrawn due to other factors, such as gender preference, but for $18.2 \%$ (140 of 768 ) of infants, the exact reasons were not mentioned.

\section{Disussion}

The outcome of ELBW infants has become a hot topic in recent decades worldwide. In this study, we confirmed that the number of ELBW infants increased rapidly from 2008 to 2017 in Guangdong Province, China. At the same time, the survival rate improved steadily year by year. These data from China provide helpful information to complement the understanding of ELBW infants from developing countries.

Similar to reports from other countries, our study has suggested an increase in ELBW infants. From the 1990s or 2000s, the number of ELBW infants began to increase in many developed countries[24-26]. In our study, we also see a significant increase in ELBW infants over the ten years, from 1.09 per 1000 discharged infants in 2008 to 2.62 per 1000 discharged infants in 2017. A 2.4-fold increase is noted. Although this is not a national population-based survey, it can partly reflect the situation of ELBW infants in China.

The improvement in the outcome of ELBW infants depends on the development of the economy and the advancement of medicine. During the past decades, the mortality rate of ELBW infants has decreased in many developed countries or regions. In Japan, the neonatal mortality rate and the mortality rate of ELBW infants during NICU stays were $13.0 \%$ and $17.0 \%$ in 2005 [9]. In the United States, the standardized mortality rates for infants weighing 501-750 grams and $751-1000$ grams in 2009 were $36.6 \%$ and $11.7 \%$, respectively[27]. In Korea, the survival rate of ELBW infants increased dramatically from $14.0 \%$ in $1985-1989$ to $69.6 \%$ in 2010 2014[28]. However, in China, it was reported that just half of ELBW infants survived in 2011[29]. In our survey, the overall survival rate of ELBW infants at discharge was $55.11 \%$, while it was $46.41 \%$ in 2011 . An encouragingly improving tendency was found, from $41.76 \%$ in 2008 to $62.02 \%$ in 2017 . This reflects the great progress gained.

The achievement of economic development can promote advancements in medicine. We found that the survival rate of ELBW infants in different regions was positively correlated with the level of economic development. Hong Kong, a developed modern city neighboring Guangdong Province but not involved in this study, reports a higher survival rate[30]. In China, specialist hospitals, such as children's hospitals or maternal and children's hospitals, have more and better facilities in neonatal care than general hospitals. As a result, a higher survival rate was noted in the specialist hospitals in our study. A similar phenomenon was found in another multicenter study from China[30]. 
Perinatal management is essential for the outcomes of ELBW infants. Many studies have shown that antenatal corticosteroids effectively decrease the mortality of preterm infants and even reduce various complications, such as NRDS, NEC, IVH and ROP[31, 32]. Although there is still some controversy regarding the side effects[33], there is a consensus that the advantages of prenatal corticosteroids outweigh the disadvantages[4,34]. Unfortunately, only $49.2 \%$ of infants' mothers received antenatal corticosteroids in this study, but this figure was $80 \%-90 \%$ in developed countries $[12,35,36]$. Therefore, this situation should be changed as soon as possible.

Interestingly, many studies have shown that the premature rupture of membranes (PROM) and pregnancy-induced hypertension (PIH) syndrome are high-risk factors for premature delivery and infant death[37, 38], but our study showed that the incidence of $\mathrm{PROM}$ and $\mathrm{PIH}$ syndrome in the survivor group was higher than that in the nonsurvivor group. Moreover, cesarean section was more common in the survivor group. A possible explanation is that PROM or PIH syndrome could have been an early warning that attracted the attention of pregnant women and led them go to the hospital for help in a timely manner. When they were admitted to the hospital, more active medical care, such as antenatal corticosteroids, cesarean section, neonatal resuscitation and pulmonary surfactant, was given. Nevertheless, the other potential reasons still need to be further studied and analyzed.

ELBW infants are unstable and tend to suffer various complications due to their prematurity. Without active life support, many infants die during the neonatal period, especially in the first 7 days of age, and some die due to critical illnesses despite receiving active treatments. In our study, $90.0 \%$ of nonsurviving infants died during the neonatal period, while nearly $68.3 \%$ died in the first 7 days, and the majority died after medical care withdrawal (Table 6). Although active treatment withdrawal in these infants is a controversial issue, it truly exists in developing countries because of the high hospital costs in addition to the high risk for later complications[39]. We can reasonably believe that the outcomes of ELBW infants will continue to improve with the continued economic development and advancement of medicine in China.

\section{Conclusion}

In conclusion, this survey presents an overall outcome of ELBW infants in China. Both the number and the survival rate of ELBW infants increased annually from 2008 to 2017. To the best of our knowledge, this study covers the largest population sample and the longest time span addressed by such studies on ELBW infants in China to date. It can provide helpful information for family consultation, clinical practice and further research. However, there are some limitations in this study. First, it is not a populationbased or nationwide study. Second, the long-term outcomes of ELBW infants are not addressed, and further studies are needed.

\section{Abbreviations}

ELBW: extremely low birth weight; GA: gestational age; BW: birth weight; NICUs: neonatal intensive care units; NRDS: neonatal respiratory distress syndrome; BPD: bronchopulmonary dysplasia; NEC: necrotizing enterocolitis; ROP: Retinopathy of prematurity; IVH: Intraventricular hemorrhage; PVL: periventricular leukomalacia; MRI: magnetic resonance imaging; Cls: confidence intervals

\section{Declarations}

\section{Acknowledgements}

We thank all the staff in the participating NICUs and the parents and infants who were involved in this survey.

\section{Authors' contributions}

FW conceptualized and designed the study, carried out the initial analyses, drafted the initial manuscript, and completed its final submitted version. CHJ, ZSF, SSH, CZY, YHD, XZY, LD, HXC, ZZ, WMH, BYY, LYH, HPR, YY, DL, SGD, CMY, BW, YGH, WZL, YLC, ZFC, $X Y L, N Y L, Z H W, B B, Y X Y$ collected data, carried out the initial analyses, interpreted data and and critically revised the manuscript. XJL, QLC, YJ, GSL, XTY, WYL, JM, BQW, CWL, XR, WS, JFL, HWH, WKY, XJR, FFW, XYL, QM, LJZ, DA, JLC, WL, YQD, YFH, YFC, YB and GHL managed data collection instruments, collected data. All authors approved the final manuscript as submitted.

\section{Funding}

Page 12/16 
This work was supported by Guangdong Science, Technology Grants (2021A1515011225 to WF), Science and Technology Planning Project of Guangzhou (202102010080 to WF)

\section{Availability of data and materials}

The datasets used and analyzed during the current study are available from the corresponding author on reasonable request.

\section{Ethics approval and consent to participate}

Data collection was approved by the Institutional Review Board of the Third Affiliated Hospital of Guangzhou Medical University. Written consent was obtained from the parents at the time of admission.

\section{Consent for publication}

Not applicable.

\section{Competing interests}

The authors have no conflicts of interest to declare.

\section{References}

1. Jacob J, Kamitsuka M, Clark RH, Kelleher AS, Spitzer AR. Etiologies of NICU deaths. Pediatrics. 2015;135(1):e59-65. doi: 10.1542/peds.2014-2967.

2. Lau C, Ambalavanan N, Chakraborty H, Wingate MS, Carlo WA. Extremely low birth weight and infant mortality rates in the United States. Pediatrics. 2013;131(5):855-60. doi: 10.1542/peds.2012-2471.

3. McGoldrick E, Stewart F, Parker R, Dalziel SR. Antenatal corticosteroids for accelerating fetal lung maturation for women at risk of preterm birth. Cochrane Database Syst Rev. 2020;12:CD004454. doi: 10.1002/14651858.CD004454.pub4.

4. Sweet DG, Carnielli V, Greisen G, Hallman M, Ozek E, Te Pas A, et al. European Consensus Guidelines on the Management of Respiratory Distress Syndrome - 2019 Update. Neonatology. 2019;115(4):432-50. doi: 10.1159/000499361.

5. Wyckoff MH, Aziz K, Escobedo MB, Kapadia VS, Kattwinkel J, Perlman JM, et al. Part 13: Neonatal Resuscitation: 2015 American Heart Association Guidelines Update for Cardiopulmonary Resuscitation and Emergency Cardiovascular Care. Circulation. 2015;132(18 Suppl 2):S543-60. doi: 10.1161/CIR.0000000000000267.

6. Agostoni C, Buonocore G, Carnielli VP, De Curtis M, Darmaun D, Decsi T, et al. Enteral nutrient supply for preterm infants: commentary from the European Society of Paediatric Gastroenterology, Hepatology and Nutrition Committee on Nutrition. J Pediatr Gastroenterol Nutr. 2010;50(1):85-91. doi: 10.1097/MPG.0b013e3181adaee0.

7. Stoll BJ, Hansen NI, Bell EF, Shankaran S, Laptook AR, Walsh MC, et al. Neonatal outcomes of extremely preterm infants from the NICHD Neonatal Research Network. Pediatrics. 2010;126(3):443-56. doi: 10.1542/peds.2009-2959.

8. Costeloe KL, Hennessy EM, Haider S, Stacey F, Marlow N, Draper ES. Short term outcomes after extreme preterm birth in England: comparison of two birth cohorts in 1995 and 2006 (the EPICure studies). BMJ. 2012;345:e7976. doi: 10.1136/bmj.e7976.

9. Itabashi K, Horiuchi T, Kusuda S, Kabe K, Itani Y, Nakamura T, et al. Mortality rates for extremely low birth weight infants born in Japan in 2005. Pediatrics. 2009;123(2):445-50. doi: 10.1542/peds.2008-0763.

10. Isayama T, Lee SK, Mori R, Kusuda S, Fujimura M, Ye XY, et al. Comparison of mortality and morbidity of very low birth weight infants between Canada and Japan. Pediatrics. 2012;130(4):e957-65. doi: 10.1542/peds.2012-0336.

11. Agarwal P, Sriram B, Lim SB, Tin AS, Rajadurai VS. Borderline viability-neonatal outcomes of infants in Singapore over a period of 18 years (1990 - 2007). Ann Acad Med Singap. 2013;42(7):328-37. 
12. Stoll BJ, Hansen NI, Bell EF, Walsh MC, Carlo WA, Shankaran S, et al. Trends in Care Practices, Morbidity, and Mortality of Extremely Preterm Neonates, 1993-2012. JAMA. 2015;314(10):1039-51. doi: 10.1001/jama.2015.10244.

13. Shah PS, Sankaran K, Aziz K, Allen AC, Seshia M, Ohlsson A, et al. Outcomes of preterm infants < 29 weeks gestation over 10 year period in Canada: a cause for concern? J Perinatol. 2012;32(2):132-8. doi: 10.1038/jp.2011.68.

14. Ishii N, Kono Y, Yonemoto N, Kusuda S, Fujimura M, Neonatal Research Network J. Outcomes of infants born at 22 and 23 weeks' gestation. Pediatrics. 2013;132(1):62-71. doi: 10.1542/peds.2012-2857.

15. Ancel PY, Goffinet F, Group E-W, Kuhn P, Langer B, Matis J, et al. Survival and morbidity of preterm children born at 22 through 34 weeks' gestation in France in 2011: results of the EPIPAGE-2 cohort study. JAMA Pediatr. 2015;169(3):230-8. doi: 10.1001/jamapediatrics.2014.3351.

16. Costeloe K, Hennessy E, Gibson AT, Marlow N, Wilkinson AR. The EPICure study: outcomes to discharge from hospital for infants born at the threshold of viability. Pediatrics. 2000;106(4):659-71. doi: 10.1542/peds.106.4.659.

17. Wu F, Liu G, Feng Z, Tan X, Yang C, Ye X, et al. Short-term outcomes of extremely preterm infants at discharge: a multicenter study from Guangdong province during 2008-2017. BMC Pediatr. 2019;19(1):405. doi: 10.1186/s12887-019-1736-8.

18. Ramaswamy VV, More K, Roehr CC, Bandiya P, Nangia S. Efficacy of noninvasive respiratory support modes for primary respiratory support in preterm neonates with respiratory distress syndrome: Systematic review and network meta-analysis. Pediatr Pulmonol. 2020;55(11):2940-63. doi: 10.1002/ppul.25011.

19. Valieva OA, Strandjord TP, Mayock DE, Juul SE. Effects of transfusions in extremely low birth weight infants: a retrospective study. J Pediatr. 2009;155(3):331-37 e1. doi: 10.1016/j.jpeds.2009.02.026.

20. Bell MJ, Ternberg JL, Feigin RD, Keating JP, Marshall R, Barton L, et al. Neonatal necrotizing enterocolitis. Therapeutic decisions based upon clinical staging. Ann Surg. 1978;187(1):1-7. doi: 10.1097/00000658-197801000-00001.

21. International Committee for the Classification of Retinopathy of P. The International Classification of Retinopathy of Prematurity revisited. Arch Ophthalmol. 2005;123(7):991-9. doi: 10.1001/archopht.123.7.991.

22. Papile LA, Munsick-Bruno G, Schaefer A. Relationship of cerebral intraventricular hemorrhage and early childhood neurologic handicaps. J Pediatr. 1983;103(2):273-7. doi: 10.1016/s0022-3476(83)80366-7.

23. Volpe JJ. Neurobiology of periventricular leukomalacia in the premature infant. Pediatr Res. 2001;50(5):553-62. doi: 10.1203/00006450-200111000-00003.

24. Fanaroff AA, Stoll BJ, Wright LL, Carlo WA, Ehrenkranz RA, Stark AR, et al. Trends in neonatal morbidity and mortality for very low birthweight infants. Am J Obstet Gynecol. 2007;196(2):147 e1-8. doi: 10.1016/j.ajog.2006.09.014.

25. Kusuda S, Fujimura M, Uchiyama A, Totsu S, Matsunami K, Neonatal Research Network J. Trends in morbidity and mortality among very-low-birth-weight infants from 2003 to 2008 in Japan. Pediatr Res. 2012;72(5):531-8. doi: 10.1038/pr.2012.114.

26. Chung SH, Bae CW. Improvement in the Survival Rates of Very Low Birth Weight Infants after the Establishment of the Korean Neonatal Network: Comparison between the 2000s and 2010s. J Korean Med Sci. 2017;32(8):1228-34. doi:

10.3346/jkms.2017.32.8.1228.

27. Horbar JD, Carpenter JH, Badger GJ, Kenny MJ, Soll RF, Morrow KA, et al. Mortality and neonatal morbidity among infants 501 to 1500 grams from 2000 to 2009. Pediatrics. 2012;129(6):1019-26. doi: 10.1542/peds.2011-3028.

28. Shim JW, Jin HS, Bae CW. Changes in Survival Rate for Very-Low-Birth-Weight Infants in Korea: Comparison with Other Countries. J Korean Med Sci. 2015;30 Suppl 1:S25-34. doi: 10.3346/jkms.2015.30.S1.S25.

29. Lin HJ, Du LZ, Ma XL, Shi LP, Pan JH, Tong XM, et al. Mortality and Morbidity of Extremely Low Birth Weight Infants in the Mainland of China: A Multi-center Study. Chin Med J (Engl). 2015;128(20):2743-50. doi: 10.4103/0366-6999.167312. 
30. Hon KL, Liu S, Chow JC, Tsang KY, Lam HS, So KW, et al. Mortality and morbidity of extremely low birth weight infants in Hong Kong, 2010-2017: a single-centre review. Hong Kong Med J. 2018;24(5):460-5. doi: 10.12809/hkmj177181.

31. Ehret DEY, Edwards EM, Greenberg LT, Bernstein IM, Buzas JS, Soll RF, et al. Association of Antenatal Steroid Exposure With Survival Among Infants Receiving Postnatal Life Support at 22 to 25 Weeks' Gestation. JAMA Netw Open. 2018;1(6):e183235. doi: 10.1001/jamanetworkopen.2018.3235.

32. Travers CP, Carlo WA, McDonald SA, Das A, Bell EF, Ambalavanan N, et al. Mortality and pulmonary outcomes of extremely preterm infants exposed to antenatal corticosteroids. Am J Obstet Gynecol. 2018;218(1):130 e1- e13. doi: 10.1016/j.ajog.2017.11.554.

33. Shanks AL, Grasch JL, Quinney SK, Haas DM. Controversies in antenatal corticosteroids. Semin Fetal Neonatal Med. 2019;24(3):182-8. doi: 10.1016/j.siny.2019.05.002.

34. Bruschettini M, Moresco L, Calevo MG, Romantsik O. Postnatal corticosteroids for transient tachypnoea of the newborn. Cochrane Database Syst Rev. 2020;3:CD013222. doi: 10.1002/14651858.CD013222.pub2.

35. Boghossian NS, McDonald SA, Bell EF, Carlo WA, Brumbaugh JE, Stoll BJ, et al. Association of Antenatal Corticosteroids With Mortality, Morbidity, and Neurodevelopmental Outcomes in Extremely Preterm Multiple Gestation Infants. JAMA Pediatr. 2016;170(6):593-601. doi: 10.1001/jamapediatrics.2016.0104.

36. Bolisetty S, Legge N, Bajuk B, Lui K, New South W, the Australian Capital Territory Neonatal Intensive Care Units' Data C. Preterm infant outcomes in New South Wales and the Australian Capital Territory. J Paediatr Child Health. 2015;51(7):713-21. doi: $10.1111 /$ jpc.12848.

37. Berhe AK, llesanmi AO, Aimakhu CO, Mulugeta A. Effect of pregnancy induced hypertension on adverse perinatal outcomes in Tigray regional state, Ethiopia: a prospective cohort study. BMC Pregnancy Childbirth. 2019;20(1):7. doi: 10.1186/s12884-019-27086.

38. Lorthe E, Torchin H, Delorme P, Ancel PY, Marchand-Martin L, Foix-L'Helias L, et al. Preterm premature rupture of membranes at 22-25 weeks' gestation: perinatal and 2-year outcomes within a national population-based study (EPIPAGE-2). Am J Obstet Gynecol. 2018;219(3):298 e1- e14. doi: 10.1016/j.ajog.2018.05.029.

39. Iglesias-Leboreiro J, Bernardez-Zapata I, Ramirez-Haua J, Gonzalez-Moran R, Rendon-Macias ME. Mortality in extremely lowbirth-weight neonates in mexico city (1985-2009). Int J Pediatr. 2010;2010:265146. doi: 10.1155/2010/265146.

\section{Figures}




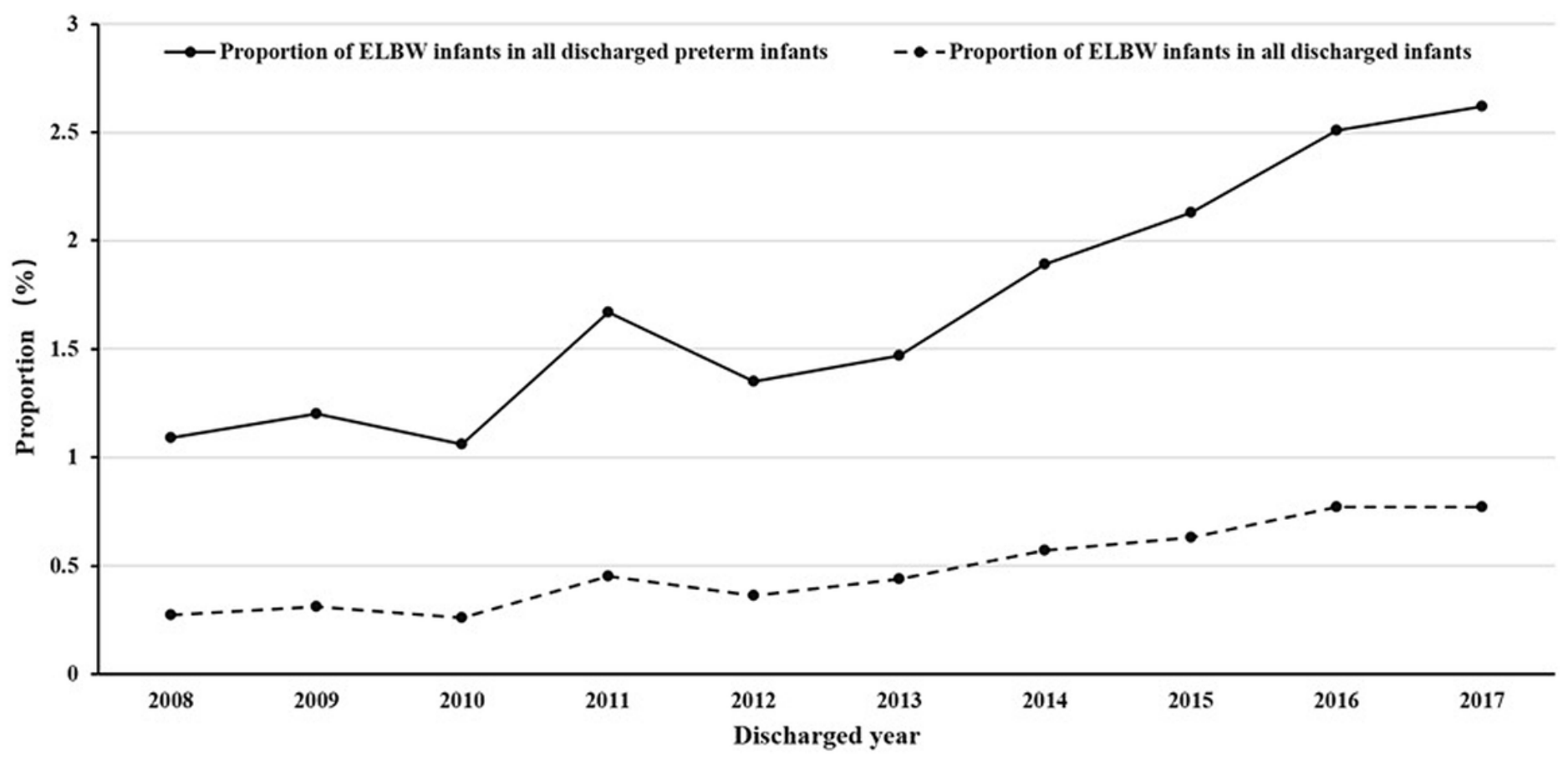

\section{Figure 1}

The proportion of ELBW infants in all discharged preterm infants or in all discharged infants from 2008 to 2017 . R $\times 2$ Chi-square test (linear-by-linear association) showed that the proportions of ELBW infants in all discharged preterm infants or in all discharged infants increased annually (both $\mathrm{P} \otimes 0.001$ ).

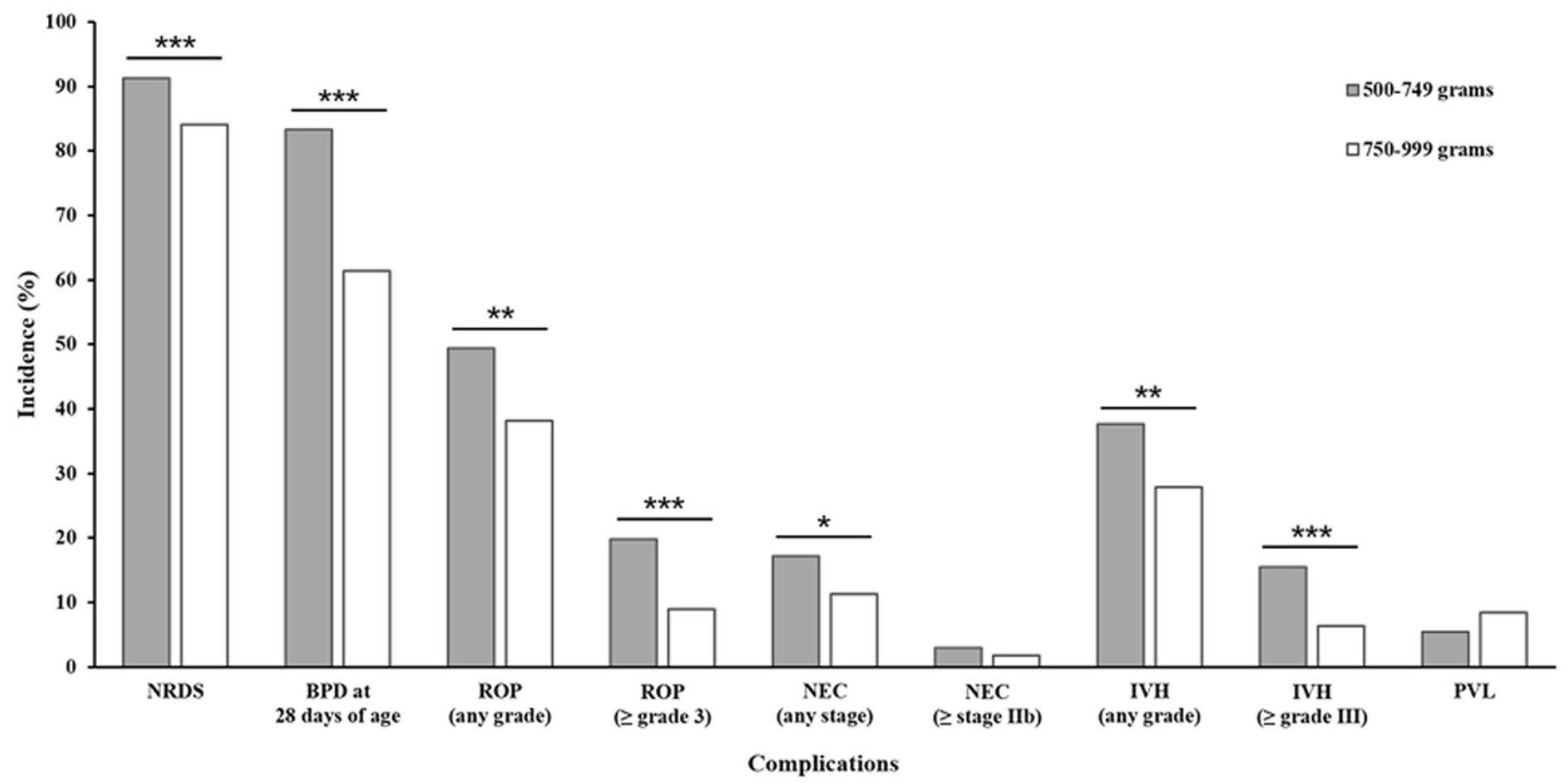

Figure 2

The incidence of complications between groups with a birth weight of 500-749 grams and 750-999 grams. NRDS: Neonatal respiratory distress syndrome; BPD: Bronchopulmonary dysplasia; ROP: Retinopathy of prematurity; NEC: Necrotizing enterocolitis;

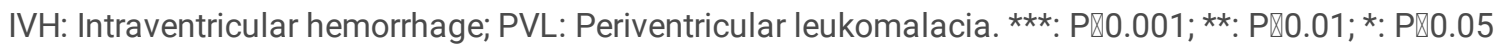

